\title{
Influence of Tire Chip Size on The Behavior of Rubberized Concrete
}

\author{
Md Roknuzzaman ${ }^{*}$, , Md Belal Hossain ${ }^{1}$, Afroja Sultana ${ }^{2}$, Abdullah Al Shourov ${ }^{3}$ \\ ${ }^{1}$ Assistant Professor, Hajee Mohammad Danesh Science and Technology University, Bangladesh \\ ${ }^{2}$ Lecturer, Prime University, Bangladesh \\ ${ }^{3}$ Graduate Student, Hajee Mohammad Danesh Science and Technology University, Bangladesh
}

\section{Keywords}

Rubberized concrete,

Scrap tire,

Green concrete,

Concrete durability.

\begin{abstract}
Performance of plain concrete with partial replacement of coarse aggregate by rubber chips derived from the waste tire is taken into consideration and an attempt is made to investigate the influence of rubber size on strength, workability, and durability. Four different size ranges of tire chips such as 4.75-9.5 mm, 9.5-12.5 mm, $12.5-19 \mathrm{~mm}$, and $19-25 \mathrm{~mm}$ are used to replace stone aggregates of corresponding sizes. A $7.5 \%$ replacement of coarse aggregate is made each time. Concrete of three different grades such as C20/25, C25/30, and C30/35 are considered. For every concrete grade, compressive strength is reduced with the addition of tire chips, but less strength loss is observed for the smaller-sized tire chips. Therefore, the best size is found to be 4.75-9.5 mm yielding a compressive strength $8.33 \%-18.48 \%$ (for different concrete grades) lower than that of corresponding control specimens. The workability of each mix based on slump value is found to increase with larger tire chip size. The durability inspection by acid curing reveals that $4.75-9.5 \mathrm{~mm}$ rubber performs best with a minimal strength reduction of $8.99 \%-16.38 \%$ as compared to the same specimen subjected to conventional water curing. Strength degradation is found to be more severe in the cases of the control specimen with lower strength.
\end{abstract}

\section{Introduction}

Nowadays, disposal of different wastes which are produced from different industries is a great concern. The waste tire is one of the most significant hazards worldwide. Thrown-out tires become the home ground for mosquitoes and rodents which are responsible for carrying many diseases. Because of the high availability, resilience, bulk, and non-biodegradability, tires are a prime target for recycling. A large number of worn-out tires are burnt for use as fuel and as a replacement of bitumen by melting them. The resulting emissions from the burning of tires are a serious threat to human health that produces a significant amount of benzene, 1, 3-butadiene, benzopyrene which are known to be more toxic than those of combustor, regardless of the fuel. But if the waste tire can be used in its original state without burning, it will be beneficial for both environment and human life. The use of tire chips as aggregate for preparing concrete is one of the potential techniques that drew the attention of the researchers. The concrete produced is said to be rubberized concrete that possesses good esthetics, acceptable workability, and a smaller unit weight than normal concrete. The rubberized concrete even proved to have the ability to absorb a large amount of plastic energy under compressive and tensile loads. It demonstrated a ductile, plastic failure mode instead of regular brittle failure [1]. Another advantage of rubberized concrete is that its brittleness index values are lower than that of normal concrete, which means that rubberized concrete has higher ductility performance than that of normal concrete [2]. In several studies, tire-borne aggregates have been proposed as a potential lightweight replacement for natural aggregates in concrete. It was reported that tire-derived aggregate (TDA) can improve the post cracking behavior of the concrete [3]. Good energy absorption and better workability of rubberized concrete produced using waste tire chips are presented in an earlier study [4]. Other than regular usage, rubberized concrete has suitability for nonstructural purposes such as lightweight concrete walls, building facades, and architectural units. They also have the potential to be used as a replacement for cement-stabilized aggregate bases under flexible pavements [5].

The tire chips can be used to replace both fine and coarse aggregates in a concrete mix in order to produce rubberized concrete. One of the challenges associated with rubberized concrete is to determine the correct amount of tire chips to be added to produce a concrete mix of a certain grade. It is suggested that rubber contents should not exceed $20 \%$ of the total aggregate volume [5]. Experiments revealed that in the regions where the environmental conditions are not corrosive, the use of concrete produced with $10 \%$ rubber aggregate is appropriate as it is economical and an effective way of recycling the discarded tires [6]. Small amounts of waste tires (TDA) in the range of $7.5 \%$ to $10 \%$ can be used in concrete with a target compressive strength of up to 4000 psi ( $\approx 28 \mathrm{MPa}$ ) [3]. Most of the related research and studies justify the use of tire chips or crumb rubbers in concrete as a partial replacement of aggregates. Another challenge in this field is to select the proper size of tire chips. Literatures acclaimed a reduced strength with increased tire chips size [7]. This study is aimed to investigate the influence of tire chip size on three major behaviors of rubberized concrete such as strength, durability, and workability. The results of the present study are expected to establish some guidelines for green concreting with tire chips which might bring about some environmental advantages.

\section{Materials and methods}

\subsection{Materials}

In this study, the materials used to produce the concrete mixtures are sand as fine aggregate, stone chips as coarse aggregate, cement as a binder, water, and tire chips as partial replacement of coarse aggregate. In addition, sulfuric acid is used for acid curing to observe durability characteristics. All these materials are collected from convenient local sources in Dinajpur, Bangladesh. Potable water is 
used for concrete preparation conditioned to room temperature. The waste tires are collected from local machinery workshops. The tire fibers without any metal wire have been selected and cut in different sizes as per requirement. The shredded tire chips are sieved using standard test sieves to separate $4.75-9.5 \mathrm{~mm}, 9.5-12.5 \mathrm{~mm}, 12.5-19$ $\mathrm{mm}$, and 19-25 $\mathrm{mm}$ size fractions. American Society for Testing and Materials (ASTM) standard procedures are adopted to determine several properties of materials [8-12]. Properties of materials are presented in Table 1.

Table 1. Material Properties

\begin{tabular}{ll}
\hline Material & Properties \\
\hline $\begin{array}{l}\text { Coarse Aggregate } \\
\text { Stone Chips) }\end{array}$ & Specific Gravity: 2.73; Water \\
& $\begin{array}{l}\text { Absorption: 1.12\%; Maximum size: } 25 \\
\text { mm; Gradation: Conforming ASTM C33 } \\
\text { [11] }\end{array}$ \\
\hline Fine Aggregates & Specific Gravity: 1.35; Water \\
(Sand) & Absorption: 2.67\%; \\
& Fineness Modulus: 2.60 \\
\hline & Specific Gravity: 1.26; Water \\
Tire Chips & Absorption: 0.03\% \\
\hline & Brand: Premier Cement (Manufactured \\
& in Bangladesh) \\
Binding Materials & Specific Gravity: 3.15; Normal \\
(Ordinary Portland & Consistency: 26\% \\
Cement) & Setting times: Initial-85 min, Final- \\
Type: CEM-I (52.5N) & 205 min \\
& 3,7 and 28-days compressive strength: \\
& 31.2 MPa, 39.7 MPa and 48.9 MPa \\
\hline Water & Potable water \\
\hline Acid & $5 \%$ Sulfuric acid \\
\hline
\end{tabular}

\subsection{Mix proportioning}

The different concrete grades $\mathrm{C} 30 / 35, \mathrm{C} 25 / 30$, and $\mathrm{C} 20 / 25$ as designated by British Standard BS 8500-2 [13] are considered as the control mixes. Mix proportioning is done following American Concrete Institute (ACI) practice ACI-211.1-91 [14]. A fixed slump value of range $75 \mathrm{~mm}$ to $100 \mathrm{~mm}$ ( 3 inches to 4 inches) is considered for each case. Based on the design criteria and laboratory trial batches, ingredients for different strengths are calculated as presented in Table 2.

Table 2. Proportions of Concrete Ingredients

\begin{tabular}{|c|c|c|c|c|}
\hline \multicolumn{2}{|c|}{ Mix Designation } & $\begin{array}{l}\text { Mix A: MA } \\
\text { (C30/35) }\end{array}$ & $\begin{array}{l}\text { Mix B: MB } \\
\text { (C25/30) }\end{array}$ & $\begin{array}{c}\text { Mix C: MC } \\
(\text { C20/25) }\end{array}$ \\
\hline \multicolumn{2}{|c|}{ Water Cement Ratio } & 0.53 & 0.61 & 0.69 \\
\hline \multirow{2}{*}{$\begin{array}{l}\text { Water } \\
\text { (kg/m3) }\end{array}$} & $\begin{array}{l}\text { Net } \\
\text { Mixing }\end{array}$ & 212 & 212 & 212 \\
\hline & $\begin{array}{l}\text { Actual } \\
\text { Added }\end{array}$ & 190 & 190 & 190 \\
\hline \multicolumn{2}{|c|}{ Cement (kg/m3) } & 400 & 346 & 307 \\
\hline \multicolumn{2}{|c|}{$\begin{array}{l}\text { Coarse Aggregate } \\
(\mathrm{kg} / \mathrm{m} 3)\end{array}$} & 1012 & 1012 & 1012 \\
\hline \multicolumn{2}{|c|}{$\begin{array}{l}\text { Fine Aggregate } \\
(\mathrm{kg} / \mathrm{m} 3)\end{array}$} & 741 & 786 & 786 \\
\hline
\end{tabular}

\subsection{Identification of the mix arrays}

For each grade of concrete, i.e., $\mathrm{MA}, \mathrm{MB}$, and $\mathrm{MC}, 3$ different size ranges of tire chips are used to replace $7.5 \%$ of the coarse aggregate of the corresponding size range. A total of 15 different mixes are, therefore tested in the laboratory as designated in Table 3.

Table 3. Designations of mix arrays

\begin{tabular}{ll}
\hline Mix Designation & Size of added tire chips \\
\hline MA1 MB1 MC1 & - \\
MA2 MB2 MC2 & $4.75-9.5 \mathrm{~mm}$ \\
MA3 MB3 MC3 & 9.5 to $12.5 \mathrm{~mm}$ \\
MA4 MB4 MC4 & $12.5-19 \mathrm{~mm}$ \\
MA5 MB5 MC4 & $19-25 \mathrm{~mm}$ \\
\hline
\end{tabular}

\subsection{Preparation of the specimens}

The different concrete grades C30/35, C25/30, and C20/25 Coarse aggregates are sieved and a well-graded aggregate is prepared for the specimens. The collected tire is cut into required sizes manually. Two types of specimens are prepared. One is the cylindrical specimens being $100 \mathrm{~mm}$ in diameter and $200 \mathrm{~mm}$ high, another is the cubic specimen having $150 \mathrm{~mm}$ sides. Concrete mixing is done following ASTM standard procedures $[15,16]$. For each mix designation, 12 cylindrical specimen and 3 cubic specimens are prepared. Among the specimens 6 cylindrical and 3 cubic specimens are tested after 28 days of standard water curing. The rest 6 cylindrical specimens are cured in water for a period of 28 days and then subjected to an additional period of 28 days in $5 \%$ sulfuric acid solution for the durability tests.

\subsection{Laboratory tests}

The concrete mixes and test specimens are subjected to workability tests, compressive strength tests, and durability tests. For workability tests, ASTM C143 standard [15] is adopted and the slump values are recorded for each mix array during its mixing process. Compressive strength tests are conducted after 28 days of curing the cylindrical and cubic specimens following the standard procedure as described in ASTM C39/C39M-12 [16]. To observe the behavior of rubberized concrete in adverse conditions, a durability test by acid curing is adopted. The specimens were cured in water for 28 days. After 28 days of curing in water, the specimens were allowed to cure for further 28 days in $5 \%$ sulfuric acid solution. At the end of acid curing, the specimens were subjected to compressive strength tests.

\section{Results and discussions}

\subsection{Influence on the workability}

Workability is the physical property that indicates the ease with which the concrete can be handled. The slump test is the most commonly used method of measuring the consistency of concrete which can be employed either in the laboratory or at the site of work. The ACI recommended slump value for typical concrete usage is presented in Table 4.

Slump values measured following ASTM C143 standard procedures are presented in Figure 1. Test results show a higher slump value for larger-sized rubber chips for all grades of concrete. Slump values of mixes with $4.75-9.5 \mathrm{~mm}$ tire chips are nearly the same as the corresponding concrete with no tire additives and the variation increases with larger tire chips. 
Table 4. Recommended slumps for various types of construction* [14]

\begin{tabular}{lcc}
\hline \multicolumn{1}{c}{ Types of Construction } & \multicolumn{2}{c}{ Slump (mm) } \\
& Maximum & Minimum \\
\hline $\begin{array}{l}\text { Reinforced foundation walls and } \\
\text { footings }\end{array}$ & 75 & 25 \\
$\begin{array}{l}\text { Plain footings, caissons, and } \\
\text { substructure walls }\end{array}$ & 75 & 25 \\
$\begin{array}{l}\text { Beams and reinforced walls } \\
\text { Building columns }\end{array}$ & 100 & 25 \\
$\begin{array}{l}\text { Pavements and slabs } \\
\text { Mass concrete }\end{array}$ & 75 & 25 \\
*The slump may be increased when chemical admixtures are used, provided \\
that the admixture-treated concrete has the same or lower water-cement or \\
water cementitious material ratio and does not exhibit segregation potential or \\
excessive bleeding
\end{tabular}

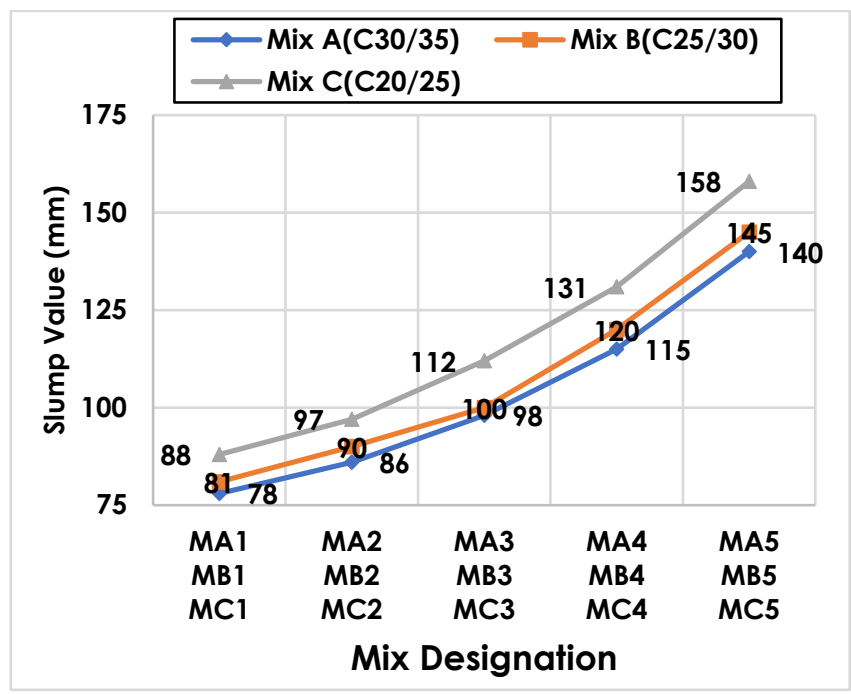

Figure 1. Workability of concrete mixes with different sizes of tire chips

\subsection{Influence on the strength}

The results of compressive strength tests are presented in Table 5.

Table 5. Compressive strength test results

\begin{tabular}{|c|c|c|c|c|}
\hline \multirow{2}{*}{\multicolumn{2}{|c|}{$\begin{array}{c}\text { Mix } \\
\text { Designation }\end{array}$}} & \multicolumn{2}{|c|}{$\begin{array}{l}\text { Compressive Strength } \\
\text { after } 28 \text { days } \\
(\mathrm{MPa})\end{array}$} & \multirow{2}{*}{$\begin{array}{c}\text { Compressive } \\
\text { Strength (cylinder) } \\
\text { after acid curing } \\
\text { (MPa) }\end{array}$} \\
\hline & & Cylinder & Cube & \\
\hline \multirow{5}{*}{$\begin{array}{c}\text { Mix A } \\
(\mathrm{C} 30 / 35)\end{array}$} & MA1 & 31.81 & 37.11 & 28.95 \\
\hline & MA2 & 29.16 & 33.9 & 25.98 \\
\hline & MA3 & 27.65 & 31.46 & 23.87 \\
\hline & MA4 & 25.35 & 28.43 & 21.10 \\
\hline & MA5 & 24.59 & 27.87 & 19.45 \\
\hline \multirow{5}{*}{$\begin{array}{c}\text { Mix B } \\
(\mathrm{C} 25 / 30)\end{array}$} & MB1 & 27.10 & 31.19 & 23.88 \\
\hline & MB2 & 23.81 & 27.04 & 20.72 \\
\hline & MB3 & 21.78 & 24.58 & 18.49 \\
\hline & MB4 & 18.93 & 21.85 & 15.34 \\
\hline & MB5 & 18.24 & 21.38 & 14.21 \\
\hline \multirow{5}{*}{$\begin{array}{c}\text { Mix C } \\
(\mathrm{C} 20 / 25)\end{array}$} & MC1 & 21.92 & 25.17 & 18.33 \\
\hline & MC2 & 17.87 & 20.21 & 14.66 \\
\hline & MC3 & 15.78 & 18.20 & 12.70 \\
\hline & MC4 & 13.89 & 16.53 & 10.79 \\
\hline & MC5 & 13.38 & 15.96 & 10.01 \\
\hline
\end{tabular}

To observe the dependency between the size of rubber chips and 28 days' compressive strength, a graphical form is presented in Figure 2.

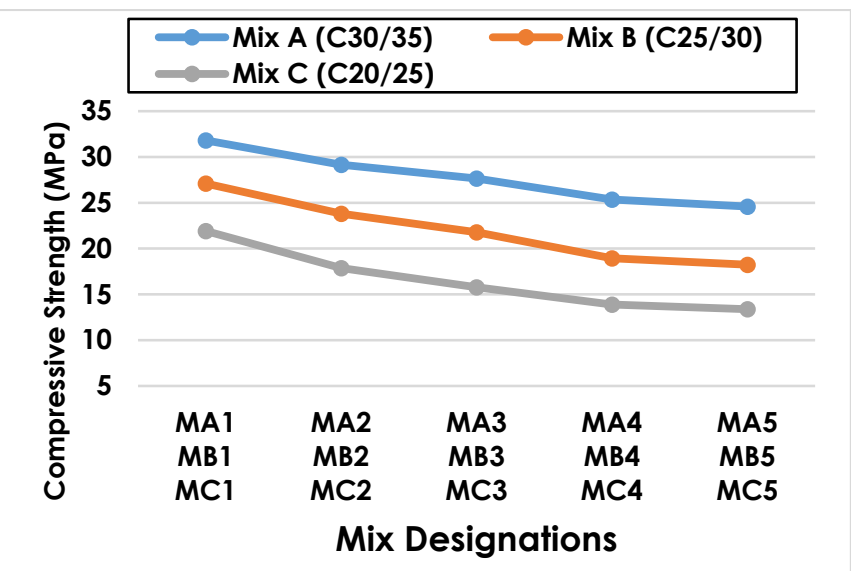

(a)

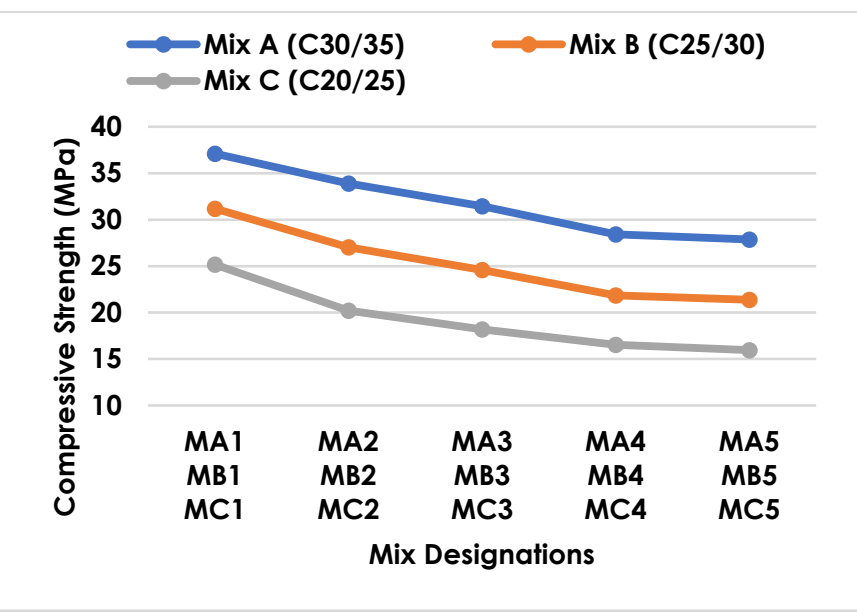

(b)

Figure 2. Compressive strength and its variation (a) Cylinder Strength, (b) Cube Strength

As the size of tire chips is reduced, compressive strength is found to be increased. The variation is at an increased rate for the concrete mixes with lower strengths. Figure 3 illustrates the percentage reduction of compressive strength (CS) with tire addition for each mix.

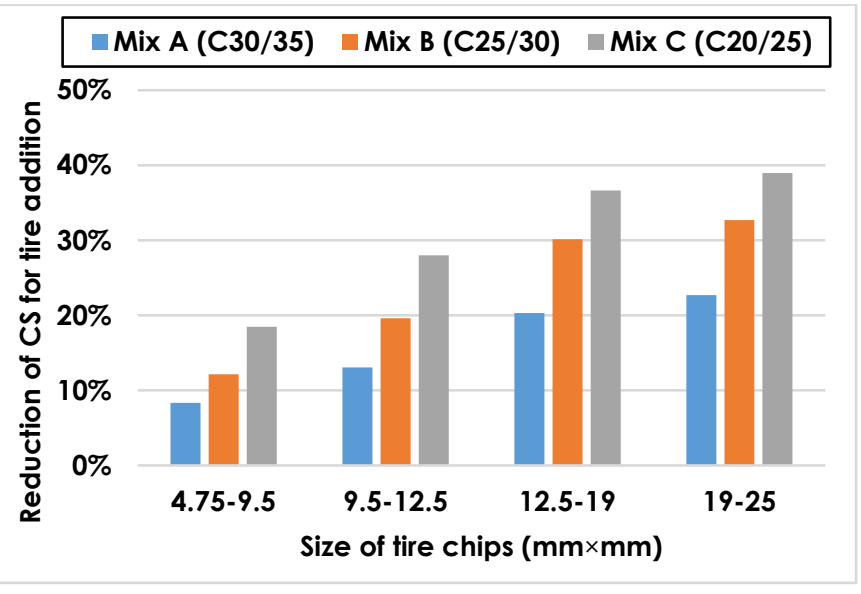

(a)

Figure 3. Reduction of compressive strength (CS) with tire chip size (a) Cylinder Strength, (b) Cube Strength (Contd.) 


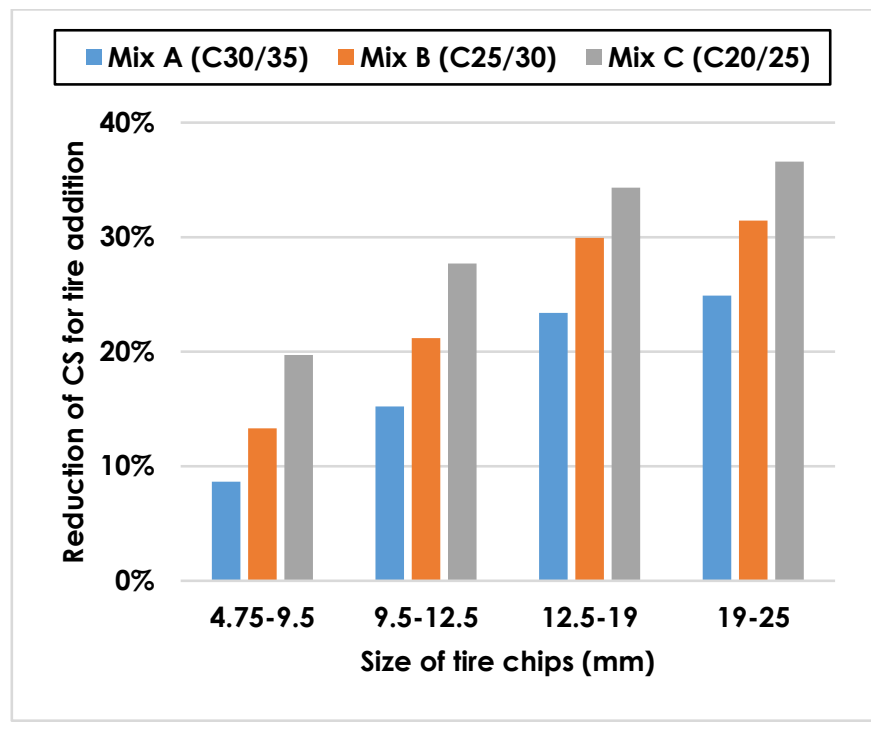

(b)

Figure 3. Reduction of compressive strength (CS) with tire chip size (a) Cylinder Strength, (b) Cube Strength

A minimum compressive strength reduction of about $8.33 \%$ is observed in the case of $\mathrm{C} 30 / 35$ concrete, whereas the corresponding minimum strength loss for C25/30 and C20/25 concrete are $12.14 \%$ and $18.48 \%$ respectively. Loss of cube strength shows a similar relationship. This reveals that the effect of tire chip addition is minimum in the case of concrete with higher strength. Another observation is that the trend of strength loss for adding larger-sized tire chips is also more prominent in the cases of concrete with lower strengths. For instance, an additional $4.75 \%$ strength (cylinder) loss is found when the tire chip size range is increased from $4.75-9.5 \mathrm{~mm}$ to $9.5-12.5 \mathrm{~mm}$ in the case of $\mathrm{C} 30 / 35$ concrete. The same loss is $7.5 \%$ in the case of $\mathrm{C} 25 / 30$ concrete and $9.5 \%$ in the case of $\mathrm{C} 20 / 25$ concrete. It is also noticeable that strength reduction for increasing the size of the tire chip up to $12.5-19 \mathrm{~mm}$ is more effective, while the additional loss for increasing size range from $12-19 \mathrm{~mm}$ to $19-25 \mathrm{~mm}$ is considerably less $(2.33 \%-2.54 \%)$

\subsection{Influence on durability}

The durability of concrete is its ability to resist weathering action, chemical attack, abrasion, or any other process of deterioration. Durable concrete will retain its original form, quality, and serviceability when exposed to its environment. Compressive strength test results after acid curing of the specimens are given in Table 5. All the specimens have lost their compressive strength to a certain amount after acid curing. Reduction of compressive strength (Cylinder) after acid curing compared to that tested after normal curing is presented graphically in Figure 4. According to ACI 318 Exposure Classes (EC) [20], among the tire added concrete mixes, only MA2, after acid curing is durable for F1 exposure conditions that demand a minimum of $24 \mathrm{MPa}$ (3500 psi) strength [19]. The mixes MB4, MB5, MC3, MC4, and MC5 fail to meet the strength requirement for any exposure condition specified in the code, as they possess strength below $17 \mathrm{MPa}$ (2500 psi). The other mixes, however, satisfy the strength requirement for FO, SO, and WO exposure conditions. Adverse condition like acidic environment has more impact on lower strength concrete and concrete produced with larger size of tire chips.

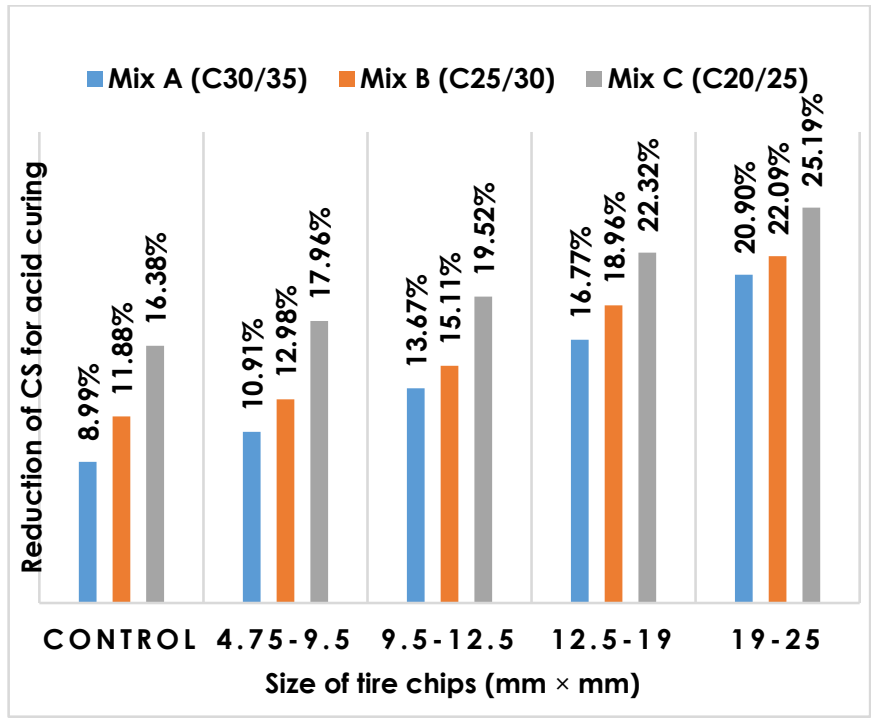

Figure 4. Loss of compressive strength after acid curing

\section{Conclusions}

The findings of the study on concrete produced with a $7.5 \%$ coarse aggregate replacement by tire chips of different sizes may be concluded as below.

$\checkmark \quad$ The addition of tire chips as a replacement of coarse aggregate of matching size increases its workability and reduces its strength. The effects are more prominent in the case of larger tire chips and lower strength concretes are more affected.

$\checkmark \quad$ The effect of tire chip size on workability is minimum for smaller-sized tire additives and it increases rapidly with increasing tire chip size. In the cases of $\mathrm{C} 30 / 35$ and $\mathrm{C} 25 / 30$ concrete, the replacement with 4.75-9.5 $\mathrm{mm}$ and 9.5-12.5 $\mathrm{mm}$ tire chips are found to meet the ACI recommended slump range for regular concreting work. In the case of C20/25 concrete only $4.75-9.5 \mathrm{~mm}$ tire chips are found to be suitable to meet the maximum slump requirement as specified in ACI 211.

$\checkmark$ For $7.5 \%$ coarse aggregate replacement with tire chips, concrete compressive strength, for both cylindrical and cubic specimens, is found to be reduced by $8.33 \%$ to $38.96 \%$ for different strength grades and different sizes of tire additives. The best result is observed for C30/35 concrete with $4.75-9.5 \mathrm{~mm}$ sized tire chips with an $8.33 \%$ loss of strength as compared to the control specimen. $4.75-9.5 \mathrm{~mm}$ sized chips replacement also yields the best result for other concrete grades.

$\checkmark \quad$ Whatever the replaced tire chip size be, loss of strength is more prominent in the cases of lower strength concretes. For $\mathrm{C} 20 / 25$ concrete a $7.5 \%$ aggregate replacement with tire chips reduces its strength as large as $38.96 \%$ compared to the control specimen with no tire additive.

$\checkmark \quad$ Tire chip size has an impact on the durability behavior of rubberized concrete. Tire chips with smaller fragments are found to produce more durable concrete than larger fragments from a compressive strength point of view. Rubberized concrete produced with 4.75-9.5 mm sized tire chips can withstand F1 exposure conditions. FO, SO, and WO exposure conditions can be met with some of the other test specimens.

A recommendation is therefore made to use smaller-sized tire chips, such as 4.75-9.5 mm size range as replacement of coarse aggregate to get the best result. Also, concrete with a higher strength grade should be considered for such modification as property degradation is more 
severe in the cases of lower strength concretes. However, in this study, only an acidic environment is considered for durability assessment. It is recommended to study the behavior of rubberized concrete under other adverse conditions to ensure its durability.

\section{Declaration of Conflict of Interests}

The authors declare that there is no conflict of interest. They have no known competing financial interests or personal relationships that could have appeared to influence the work reported in this paper.

\section{References}

[1.] Eldin, N.N., Senouci, A.B., Measurement and prediction of the strength of rubberized concrete. Cement and Concrete Composites 16.4 (1994) 287-298. DOI : https://doi.org/10.1016/0958-9465(94)90041-8

[2.] Zheng, L., Huo, X.S., Yuan, Y., Strength, modulus of elasticity, and brittleness index of rubberized concrete. Journal of Materials in Civil Engineering 20.11(2008) 692-699. DOI : https://doi.org/10.1061/(ASCE)0899-1561(2008)20:11(692)

[3.] Siringi, G., Abolmaali, A., Aswath, P.B., Properties of concrete with tire derived aggregate partially replacing coarse aggregates. The Scientific World Journal 2015 (2015) 863706. DOI : https://doi.org/10.1155/2015/863706

[4.] Aiello, M.A., Leuzzi, F., Waste tyre rubberized concrete: Properties at fresh and hardened state. Waste management 30(2010) 16961704. DOI : https://doi.org/10.1016/j.wasman.2010.02.005

[5.] Khatib, Z.K., Bayomy, F.M., Rubberized Portland cement concrete. Journal of materials in civil engineering 11.3(1999) 206-213.

DOI : https://doi.org/10.1061/(ASCE)0899-1561(1999)11:3(206)

[6.] Topçu, I.B., Demir, A., Durability of rubberized mortar and concrete. Journal of materials in Civil Engineering 19.2(2007) 173-178. DOI : https://doi.org/10.1061/(ASCE)0899-1561(2007)19:2(173)

[7.] Roychand, R., Gravina, R.J., Zhuge, Y., Ma, X., Youssf, O., Mills, J.E., A comprehensive review on the mechanical properties of waste tire rubber concrete. Construction and Building Materials 237(2020) 117651.

DOI : $\underline{\text { https://doi.org/10.1016/j.conbuildmat.2019.117651 }}$

[8.] ASTM C128-15. Standard test method for relative density (specific gravity) and absorption of fine aggregate. American Society for Testing and Materials: West Conshohocken, PA, USA, (2015). www.astm.org

[9.] ASTM C29-09. Standard test method for bulk density ("Unit Weight") and voids in aggregate. American Society for Testing and Materials: West Conshohocken, PA, USA. (2009). www.astm.org

[10.] ASTM C136-06. Standard test method for sieve analysis of fine and coarse aggregates. American Society for Testing and Materials: West Conshohocken, PA, USA. (2006). www.astm.org

[11.] ASTM C33/C33M-18. Standard Specification for Concrete Aggregates. American Society for Testing and Materials: West Conshohocken, PA, USA. (2018). www.astm.org

[12.] ASTM C109/C109M-20b. Standard Test Method for Compressive Strength of Hydraulic Cement Mortars (Using 2-in. or [50 mm] Cube Specimens). American Society for Testing and Materials: West Conshohocken, PA, USA. (2020). www.astm.org
[13.] BSI BS8500-2. Concrete: Part 2: Specification for constituent materials and concrete. (2020).

[14.] ACI 211.1-91. Standard Practice for Selecting Proportions for Normal, Heavyweight, and Mass Concrete. American Concrete Institute. (1991).

[15.] ASTM C143/C143M-15a. Standard Test Method for Slump of Hydraulic-Cement Concrete. American Society for Testing and Materials: West Conshohocken, PA, USA. (2015). www.astm.org

[16.] ASTM C39/C39M-12. Standard test method for compressive strength of cylindrical concrete specimens. American Society for Testing and Materials: West Conshohocken, PA, USA. (2012). www.astm.org

[17.] Topçu, İ.B., Bilir, T., Experimental investigation of some fresh and hardened properties of rubberized self-compacting concrete. Materials \& Design 30.8 (2009) 3056-3065. DOI : https://doi.org/10.1016/j.matdes.2008.12.011

[18.] Li, N., Long, G., Ma, C., Fu, Q., Zeng, X., Ma, K., Xie, Y., Luo, B. Properties of self-compacting concrete (SCC) with recycled tire rubber aggregate: A comprehensive study. Journal of Cleaner Production 236(2019) 117707. DOI : https://doi.org/10.1016/j.jclepro.2019.117707

[19.] ACI 318-08. Building code requirements for structural concrete and commentary, American Concrete Institute. (2008).

\section{How to Cite This Article}

Roknuzzaman, M., Hossain, M.B., Sultana, A. and Shourov, A.A., Influence of tire chip size on the behavior of rubberized concrete, Civil Engineering Beyond Limits, 3 (2021), 18-22. https://doi.org/10.36937/cebel.2021.003.004 